Bull. Mater. Sci., Vol. 16, No. 1, February 1993, pp. 73-83. (C) Printed in India.

\title{
Studies on certain wood-plastic-composites prepared by gamma irradiation
}

\author{
P T THOMAS, B R S BABU* and K NEELAKANDAN* \\ Government Arts and Science College, Calicut 673018, India \\ *Department of Physics, University of Calicut, Calicut 673635, India
}

MS received 15 July 1991; revised 2 April 1992

\begin{abstract}
Wood-plastic-composites have been prepared using locally available soft wood and commercial monomers by vacuum impregnation of monomer in wood and subsequent polymerization by gamma irradiation. The irradiation was performed by means of a ${ }^{60} \mathrm{Co}$ source of strength $50,000 \mathrm{Ci}$ at $0.2 \mathrm{Mrad} / \mathrm{h}$. The radiation dosage required for maximum conversion of monomer into polymer was less than $2 \mathrm{Mrad}$ except styrene which required a much larger dose of about $10 \mathrm{Mrad}$. The impregnation efficiency was found to be more for wood with high pore volume. The impregnation efficiency also depended on the ambient pressure: the more the vacuum, the more was the impregnation efficiency. Mechanical strength of the composites was found to be enhanced and water absorption considerably reduced. X-ray diffraction studies showed that the crystallinity of the cellulose did not get affected by the radiation polymerization which suggested that grafting of polymer on to the cell wall took place only in the amorphous regions.
\end{abstract}

Keywords. Wood-plastic-composites; gamma irradiation; X-ray diffraction; vacuum impregnation.

\section{Introduction}

The total annual production of wood from forests in India is estimated at 26 million cubic meters of which roughly one-third is used by industries and the rest as fuel. In contrast, in North America industrial wood forms $83 \%$ of the total wood consumed. It is therefore imperative that while on one hand the maximum quantity of timber be extracted from forests and its conversion improved, and on the other modern timber designs be developed. The growing demand for high grade timber can be met only if the weaker and less durable varieties, which now serve mostly as fuelwood, can be more efficiently utilized.

Conventional wood treatment with coaltar creosote, arsenic and other inorganic salts is well-known in India. The Forest Research Institute, Dehra Dun, and the Indian Standards Institution, New Delhi, have compiled the existing knowhow in this field (Forest Research Institute 1961; Indian Standards Institute 1966). The development of polymer impregnated wood in the West was adapted and explored in the Indian context by the Bhabha Atomic Research Centre, Bombay (Iya 1968). It was felt that utilization of low grade wood in the formation of wood-polymer-composites (WPC) was very promising in view of its need for conserving the limited resources of superior woods.

With this background, in the present work, we have prepared WPC by impregnating certain locally available soft wood species with commercially available monomers and polymerising it by irradiation. The woods used are Erthryna stricta Roxb. (Murukku) and Hevea brasiliensis (H.B.K.) Muell. Arg. (Rubber) along with a variety of monomers, viz. styrene, methylmethacrylate, acrylonitrile, vinyl acetate and their mixtures. 


\section{Experimental details}

Wood samples were collected from timber sapwood. To ensure uniformity and homogeneity of tracheids, the pit system and the ray cell samples were prepared from the same portion of the timber, as far as possible, for a particular set of experiments. All the samples were cut along the length of the wood, the lateral sides respectively parallel to the radial and the tangential directions. Defective samples like knots were summarily rejected.

The size and shape of the samples were dictated by the requirements of the mechanical tests conducted on the impregnated samples. These were: $12.0 \times 2.5 \times 0.5 \mathrm{~cm}$ : tensile test; $5.0 \times 2.0 \times 2.0 \mathrm{~cm}$ : compression test and $12.0 \times 2.5 \times 0.5 \mathrm{~cm}$ : rupture test.

The average densities of the two species of timber was obtained by measuring volume and weight of 500 samples of each species. The values of these densities are given in table 1. The moisture content (MC) is a significant parameter in monomer penetration and grafting reaction. To study the effect of $M C$, we selected two batches of samples. One set of samples was prepared during the summer months and stored in shelf for several days enabling it to equilibrate with the atmosphere. The other set was similarly prepared during the monsoon season. The MC of both the samples was measured by finding the difference in their weights before and after heating. A temperature of $50^{\circ} \mathrm{C}$ was found to be sufficient. After measuring a large number of samples, the average value of $\mathrm{MC}$ obtained is given (table 1 ).

Different types of monomers have been used to prepare WPC. Vinyl acetate is one such which is a soft polymer. Combination of vinyl acetate with hard polymers like methylmethacrylate or acrylonitrile could yield better mechanical properties for WPC. Vinyl acetate and styrene do not mix. The heat of polymerization is much higher in styrene acrylonitrile system than that in styrene (Rotariu and Mott 1968). These considerations led to the following combinations of monomers:

$$
\begin{array}{lll}
\text { Methylmethacrylate-acrylonitrile } & 1: 1 & \text { (V/V) } \\
\text { Vinyl acetate-acrylonitrile } & 1: 1 & \text { (V/V) }
\end{array}
$$

The monomers available commercially (supplied by SISCO Research Laboratories, Bombay, and Loba-Chemie Indoaustranal Co., Bombay) with impurities was washed using $5 \%$ aqueous sodium hydroxide and distilled water and dried over calcium chloride. The samples obtained were subjected to evacuation in a specially designed vacuum desiccator. About ten to fifteen samples were impregnated at a time. A rotary pump was used for evacuation. Measurement of pressure was done by a manometer. Evacuation helped to remove the trapped air which led to the uniform penetration of monomer into the wood during impregnation. A low pressure was maintained in the desiccator for $30 \mathrm{~min}$.

Table 1. Physical characteristics of murukku and rubber.

\begin{tabular}{lcccc} 
& & & \multicolumn{2}{c}{ Average MC $(\%)$} \\
\cline { 4 - 5 } Species & Density $\left(\mathrm{kg} / \mathrm{m}^{3}\right)$ & $\begin{array}{c}\text { Pore volume } \\
(\%)\end{array}$ & Low & High \\
\hline Murukku & $280 \pm 40$ & 81.81 & $13 \cdot 1 \pm 1.2$ & $27.6 \pm 1.8$ \\
Rubber & $720 \pm 86$ & 53.24 & $12.4 \pm 1.3$ & $26.5 \pm 1.5$ \\
\hline
\end{tabular}


After evacuation, the vacuum pump was isolated from the desiccator. The monomer was introduced into the evacuated chamber. Sufficient monomer was introduced to keep the wood samples covered at all times during loading phase. After isolating the monomer inlet tube, the samples were kept soaked in the monomer under vacuum for $10 \mathrm{~h}$. They were then taken out and any traces of monomer on the surface of the samples were dried. They were then weighed and wrapped in thin aluminium foils to prevent the loss of monomer by evaporation.

The samples were irradiated in a Panoramic Batch Irradiator (PANBIT) supplied by the Bhabha Atomic Research Centre, Bombay, available at the Western India Plywood Manufacturing Co., Cannanore, Kerala. The source was ${ }^{60} \mathrm{Co}$ of strength $50,000 \mathrm{Ci}$. A dose rate of $0.25 \mathrm{Mrad} / \mathrm{h}$ was chosen in the present experiments. The irradiated samples were oven dried to remove unpolymerized monomer present in the wood. All the samples were weighed and the polymer content inside the wood estimated.

Mechanical properties of WPC were studied by measuring tensile strength (TS), compressive strength (CS) and the modulus of rupture (MOR). Measurements were done on the Universal Testing Machine available at the Western India Plywood Manufacturing Co., where the irradiation was performed. The testing modes confirmed to the German standards DIN 52 188, DIN 52185 and DIN 52 186 for TS, CS and MOR respectively. In order to enable the mechanical tests on WPC to be compared with those on the control samples, the WPC samples were equilibrated to the atmosphere for long duration of time. Mechanical measurements were done on a large number of samples and the average taken.

Water absorption of both treated and untreated samples were studied by soaking the samples in water for long durations and weighing them at different intervals of time. Water absorption is represented in percentage by the relation

$$
\begin{aligned}
\text { Water absorption }(\%)= & {[(\text { wt. of water absorbed }) /} \\
& \text { (original wt. of sample })] \times 100
\end{aligned}
$$

WPC is a mixture of amorphous as well as crystalline phases. Consequently, its $\mathrm{X}$-ray diffraction pattern is complex. It becomes extremely tedious to derive quantitative information regarding the amount of each phase present. However, it is possible to compare the patterns with reference patterns to identify or characterize the phases present. In the present investigation, an attempt is made to identify the phases present but no attempt is made to quantitatively determine their relative amounts.

The samples were cut into flat thin specimens. The surface of WPC contained less amount of polymer due to evaporation during impregnation and irradiation. To avoid uneven distribution of polymer, a thin outer layer was removed. The samples were then well smoothened with a file, cleaned using detergent, distilled water and acetone. Diffraction scans of these as well as those of control samples were recorded.

\section{Results and discussion}

\subsection{Radiation dose for polymerization}

In order to find out the radiation dose for complete polymerization, the following standard procedure (Iya 1968) was followed. Wood samples having low MC (table 1) 
Table 2. Percent conversion of monomers in murukku and rubber.

\begin{tabular}{|c|c|c|c|c|c|c|c|c|c|c|c|c|}
\hline \multirow[t]{2}{*}{$\begin{array}{l}\text { Total dose } \\
\text { (Mrad) }\end{array}$} & \multicolumn{2}{|c|}{ MMA } & \multicolumn{2}{|c|}{ Styrene } & \multicolumn{2}{|c|}{$\begin{array}{l}\text { Acrylo- } \\
\text { nitrile }\end{array}$} & \multicolumn{2}{|c|}{$\begin{array}{c}\text { Vinyl } \\
\text { acetate }\end{array}$} & \multicolumn{2}{|c|}{$\begin{array}{l}\text { Acrylonitrile } \\
\text { (MMA) }\end{array}$} & \multicolumn{2}{|c|}{$\begin{array}{l}\text { Acrylonitrile- } \\
\text { vinyl acetate }\end{array}$} \\
\hline & I & II & 1 & II & I & II & I & II & I & II & I & II \\
\hline 0.5 & 12.5 & $13 \cdot 7$ & - & - & $12 \cdot 6$ & $15 \cdot 1$ & $15 \cdot 4$ & $16 \cdot 2$ & $25 \cdot 0$ & $32 \cdot 1$ & $20 \cdot 3$ & $26 \cdot 4$ \\
\hline 1.0 & 34.5 & $36 \cdot 1$ & $10 \cdot 1$ & $11 \cdot 2$ & $30 \cdot 3$ & 38.5 & $40 \cdot 2$ & 46.5 & $60 \cdot 0$ & 78.0 & $60 \cdot 0$ & $70 \cdot 5$ \\
\hline 1.25 & 65.2 & $74 \cdot 1$ & - & - & 55.5 & 68.7 & $70 \cdot 2$ & $82 \cdot 1$ & 72.5 & $81 \cdot 4$ & 78.5 & $87 \cdot 2$ \\
\hline 1.50 & $81 \cdot 2$ & 98.2 & - & - & $78 \cdot 2$ & 97.6 & $80 \cdot 0$ & 98.6 & 98.4 & $98 \cdot 1$ & 98.0 & $98 \cdot 2$ \\
\hline 1.75 & 98.5 & - & - & - & 98.2 & - & 98.4 & - & - & - & - & - \\
\hline $3 \cdot 0$ & - & - & 12.8 & $14 \cdot 3$ & - & - & - & - & - & - & - & - \\
\hline 5.0 & - & - & $18 \cdot 4$ & $20 \cdot 5$ & - & - & - & - & - & - & - & - \\
\hline 7.0 & - & - & $50 \cdot 2$ & $56 \cdot 5$ & - & - & -- & - & - & - & - & - \\
\hline 8.0 & - & - & 77.8 & 87.8 & - & - & - & - & - & - & - & - \\
\hline $9 \cdot 0$ & - & - & 88.6 & 98.2 & - & - & - & - & - & - & - & - \\
\hline $10 \cdot 0$ & - & - & 96.5 & - & - & - & - & - & - & - & - & - \\
\hline
\end{tabular}

(I) Murukku and (II) rubber.

were impregnated under pressure of 1 torr $\left(1.333 \times 10^{2} \mathrm{~Pa}\right)$ and irradiated. Weight of the samples removed from the radiation chamber was measured. The samples were heated in an oven at $50^{\circ} \mathrm{C}$ to remove unpolymerized monomer. Heating was continued until the sample attained a constant weight in successive weighings. The percentage conversion is given by

Conversion $(\%)=(w t$. of dry sample after polymerization and removal of the unpolymerized monomer - wt. of dry bare sample) $\times 100 /$ (wt. of sample just after polymerization - wt. of dry bare sample)

In all weighings, the average weight of 10 samples was taken. The results are given in table 2 .

From the above results, the following conclusions can be drawn: (i) For a given dose, the percentage of conversion of the monomer is greater in rubber than in murukku. Such variations of total dose required for the polymerization of a particular monomer in different woods are commonly observed (Felice 1968). (ii) For the monomers, viz. MMA, acrylonitrile, vinyl acetate and the combinations, acrylonitrileMMA and acrylonitrile-vinyl acetate, the dose required for maximum conversion is less than $2 \mathrm{Mrad}$. However, for styrene, a comparatively higher dose of about $10 \mathrm{Mrad}$ in murukku and $9 \mathrm{Mrad}$ in rubber is necessary for maximum conversion. The higher dose required for styrene is due to the protecting effect of benzene rings of styrene (Czvikovazky and Dobo 1968). (iii) The maximum percentage of conversion in all the samples is slightly less than 100 . This may be due to the fact that during heating the absorbed moisture and other volatile compounds in the wood evaporate and, therefore, the oven dry weight is always less than the weight just after polymerization. Samples with high MC gave similar results.

The impregnation efficiency can be described in terms of the pore volume utilization which is defined as the ratio of the sorbed volume of monomer to the pore volume of the wood (Czvikovazky and Dobo 1968). The volume of the pores can be estimated 
Table 3. Impregnation efficiency of different monomer-wood systems

\begin{tabular}{|c|c|c|c|c|c|c|}
\hline Wood & Monomer & $\begin{array}{c}1 \text { torr } \\
(1 \cdot 333 \\
\left.\times 10^{2} \mathrm{~Pa}\right)\end{array}$ & $\begin{array}{l}100 \text { torr } \\
(1.333 \\
\left.\times 10^{4} \mathrm{~Pa}\right)\end{array}$ & $\begin{array}{c}200 \text { torr } \\
(2.666 \\
\left.\times 10^{4} \mathrm{~Pa}\right)\end{array}$ & $\begin{array}{l}300 \text { torr } \\
(3.999 \\
\left.\times 10^{4} \mathrm{~Pa}\right)\end{array}$ & $\begin{array}{l}400 \text { torr } \\
(5.332 \\
\left.\times 10^{4} \mathrm{~Pa}\right)\end{array}$ \\
\hline & MMA & 0.91 & 0.83 & 0.73 & 0.60 & 0.43 \\
\hline & Styrene & 0.93 & 0.84 & $0 \cdot 70$ & 0.59 & \\
\hline & Vinylacetate & 0.98 & 0.81 & 0.66 & 0.59 & \\
\hline \multirow[t]{6}{*}{ Murukku } & Acrylonitrile & 0.94 & 0.82 & 0.76 & & \\
\hline & $\begin{array}{l}\text { Acrylonitrile + } \\
\text { MMA }\end{array}$ & 0.90 & 0.85 & 0.69 & & \\
\hline & $\begin{array}{l}\text { Acrylonitrile + } \\
\text { Vinyl } \\
\text { acetate }\end{array}$ & $0-94$ & 0.87 & 0.68 & & \\
\hline & MMA & 0.87 & 0.77 & 0.69 & & \\
\hline & Styrene & 0.74 & 0.70 & 0.66 & & \\
\hline & Vinyl acetate & 0.82 & 0.65 & $0 \cdot 61$ & & \\
\hline \multirow[t]{4}{*}{ Rubber } & Acrylonitrile & 0.87 & 0.79 & 0.70 & & \\
\hline & Acrylonitrile & & & & & \\
\hline & + MMA & 0.76 & 0.71 & 0.67 & 0.59 & \\
\hline & $\begin{array}{l}\text { Acrylonitrile } \\
\text { + Vinyl } \\
\text { acetate }\end{array}$ & 0.75 & 0.70 & 0.67 & 0.55 & \\
\hline
\end{tabular}

in the free volume model by the formula,

$$
V_{f}=V\left[1-\rho / \rho_{w}\right],
$$

where $V_{f}$ is the free (pore) volume, $V$, the total volume of the sample, $\rho$, the bulk density and $\rho_{w}$, the density of the hypothetical, absolutely dense wood substance, its value for every kind of wood being $1540 \mathrm{~kg} / \mathrm{m}^{3}$. From the densities the percent pore volume was calculated for the two species of wood. The values are given in table 1 . As is evident, murukku is more porous than rubber. From the knowledge of the weight and density of each sample, the total volume and the pore volume of each sample was then calculated.

The difference in weight of the sample just after impregnation and that of the bare sample gives the weight of the monomer impregnated. The volume of the impregnated monomer was calculated by dividing the weight by its density. The densities of the monomer mixtures were taken to be the average of the densities of individual monomers. The ratio of the volume of impregnated monomer to the volume of the pores (pore volume utilization/impregnation efficiency) was calculated for each sample.

The impregnation efficiency as a function of pressure in the impregnation chamber is given in table 3 for samples with low MC. Samples with high MC have about the same impregnation efficiency as those with low MC.

For the lowest attained vacuum of 1 torr $\left(1.33 \times 10^{2} \mathrm{~Pa}\right)$, the impregnation efficiency was as high as 90 to $99 \%$ in murukku and 74 to $87 \%$ in rubber. The viscosity of the monomer did not seem to play any significant role in the impregnation efficiency. For, if it did, vinyl acetate having the greatest viscosity should have had the lowest impregnation efficiency, which was not found so in our experiments. The impregnation efficiency was found to depend on the type of wood used. For the same pressure, the impregnation efficiency was lower in rubber than in murukku. 
By choosing the appropriate pressure in the impregnation chamber, it was possible to tailor the samples for a given monomer uptake and polymer loading.

\subsection{Mechanical properties}

Figures 1 and 2 give the tensile strength of some of the murukku based and rubber based WPC samples as a function of radiation dose. Different batches of samples were irradiated for different times which amounted to different radiation doses. This in turn enabled the samples to have different polymer loadings. By the rule of mixtures (Moore et al 1983; Brebner et al 1985), samples with the maximum polymer loading had the largest strength. Maximum polymer loading took place at the dose at which the monomer to polymer conversion was maximum (table 2). Therefore, the mechanical properties showed a maximum at these doses. However, higher doses entailed degradation of wood and hence there was a gradual reduction of strength of WPC as the radiation dose was increased.

The average tensile strength of control samples of rubber was $56 \mathrm{MPa}$ and that of murukku, $20 \mathrm{MPa}$. In the control samples of rubber, tensile strength increased slightly with dose and reached a maximum of $66.5 \mathrm{MPa}$ at a dose of $1 \mathrm{Mrad}$ and in murukku, $23 \mathrm{MPa}$ at a dose slightly above $1 \mathrm{Mrad}$. This marginal increase was due to the development of hydrogen bonds in wood when low gamma doses were used.

In styrene impregnated rubber and murukku maximum tensile strength occurred at

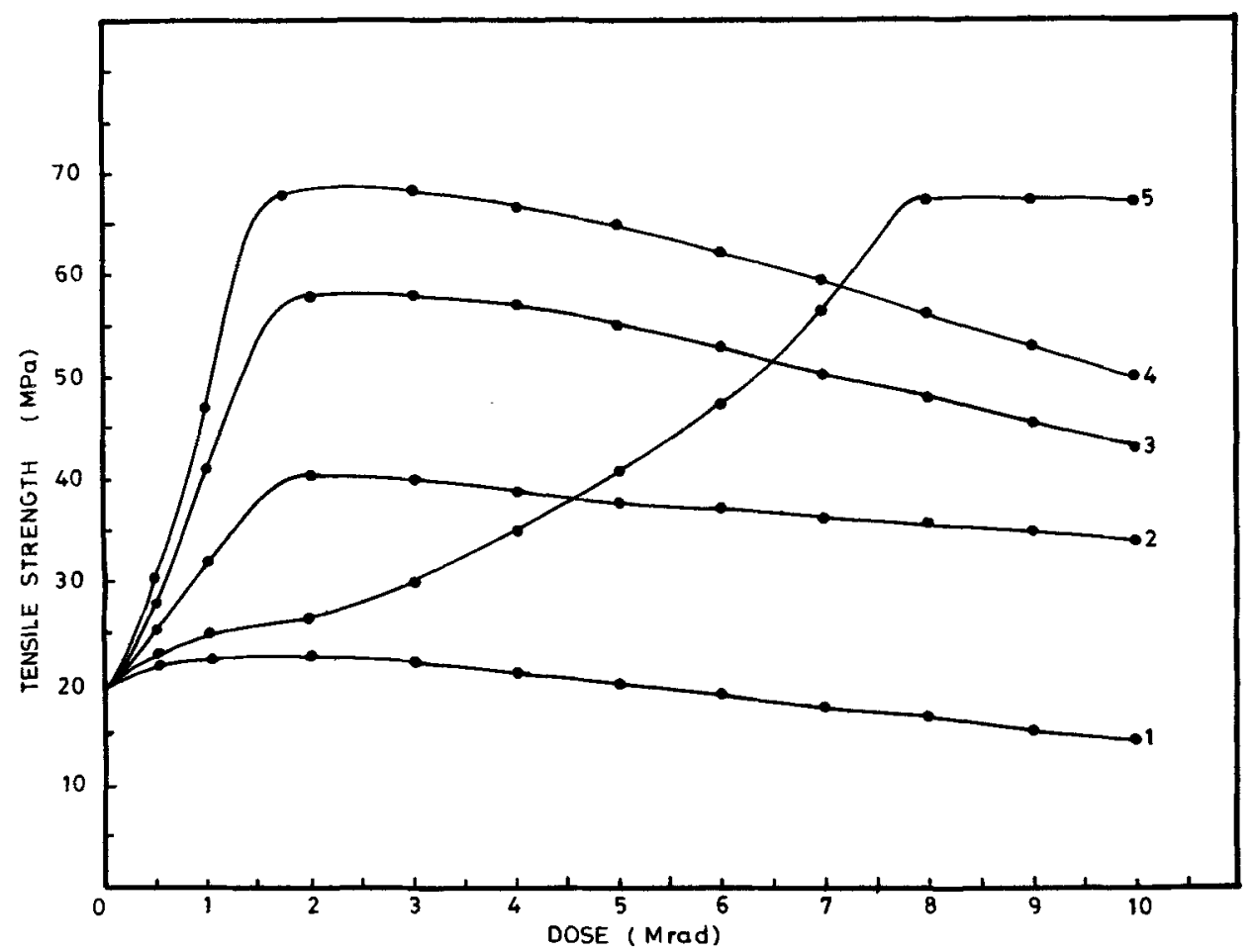

Figure 1. TS of murukku based composites. 1. Control, 2. p-(acrylonitrile + vinyl acetate), 3. p-MMA, 4. p-(acrylonitrile + MMA) and 5. p-styrene. 


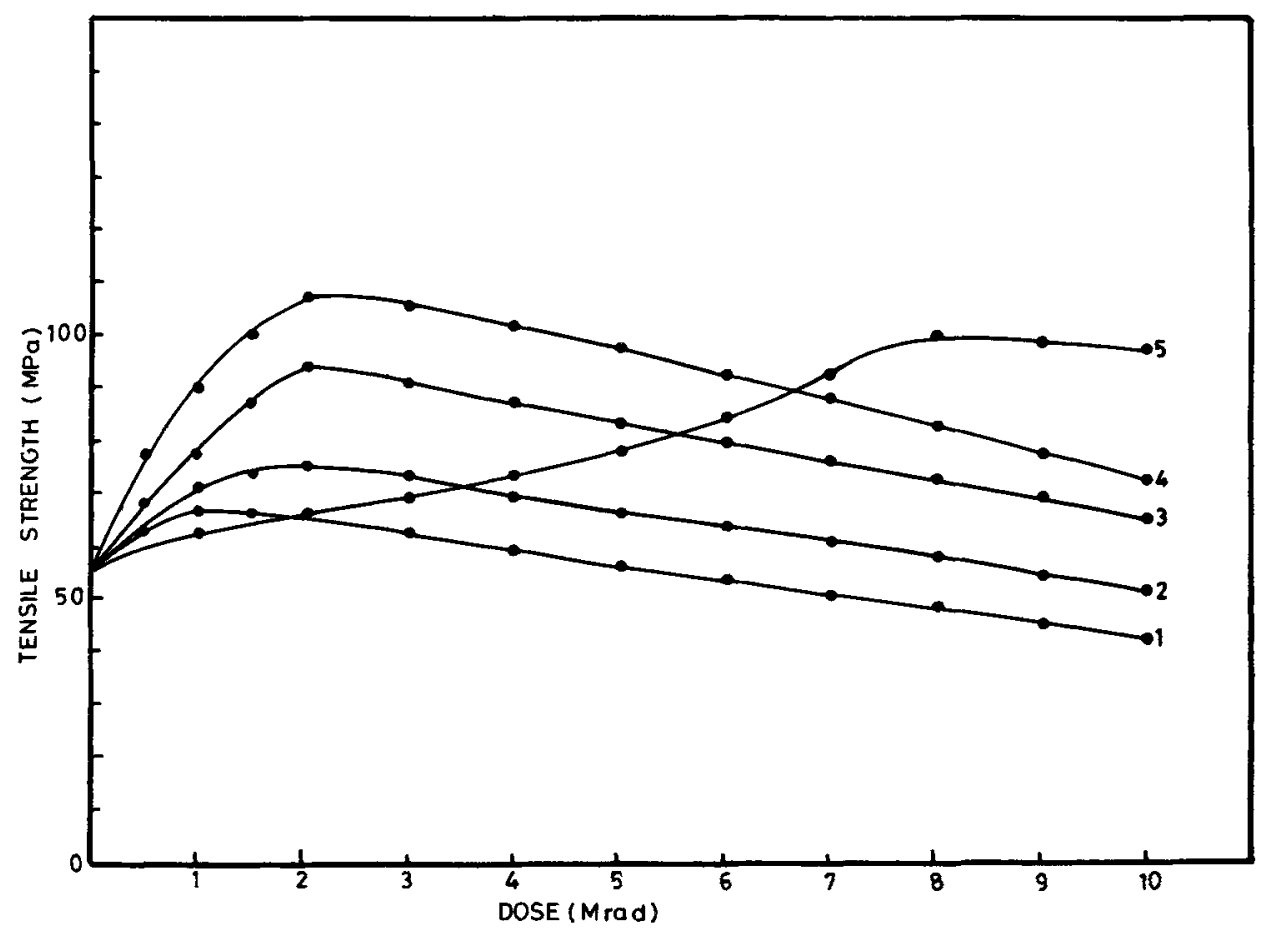

Figure 2. TS of rubber based composites. 1. Control, 2. p-(acrylonitriles + vinyl acetate), 3. p-MMA, 4. p-(acrylonitrile + MMA) and 5. p-styrene.

$8 \mathrm{Mrad}$, even though the maximum conversion occurred at a dose of $9 \mathrm{Mrad}$ for rubber and $10 \mathrm{Mrad}$ for murukku. This discrepancy was due to the following factors: due to experimental difficulties, the points on the curves could not be brought closer enough to identify the exact value of the dose at which the maximum of tensile strength occurred. Also at such high doses, the degradation of the wood meal acted against the enhancement of mechanical properties.

In the case of samples loaded with MMA and combinations of monomers, viz acrylonitrile-vinyl acetate and acrylonitrile-MMA, the behaviour of tensile strength as a function of dose was similar to that of styrene impregnated wood. Vinyl acetate being a soft polymer, its presence in wood either alone or in combination with other polymers was less effective in enhancing its strength. For example, the composite, acrylonitrile-MMA-murukku (curve 4) showed a maximum enhancement of about $185 \%$ in tensile strength compared to the control sample whereas for the composite, acrylonitrile-vinyl acetate-murukku (curve 2) the corresponding value was $74 \%$.

From the above it was observed that all the elastic moduli increased, the values of which differed widely depending on the specimen, the monomer used and the level of polymer loading. Such trends have been reported earlier (Mayer 1981; Schaudy et al 1982; Brebner et al 1985). The difference in the moisture content of the starting wood sample was not found to influence the mechanical properties significantly. The general trend of variation of modulus of rupture and compressive strength was similar to that of tensile strength. 


\subsection{Water absarption}

Representative samples of WPC prepared from low MC wood impregnated and irradiated to the dose for maximum conversion followed by oven drying were allowed to soak in water for various intervals of time. Water absorption ( $\%$ by weight) for each sample was calculated. Average values of water absorption for batches of samples soaked in water for different times are given in figures 3 and 4.

In control samples, water absorption was as high as $300 \%$ in murukku and $82 \%$ in rubber. The larger absorption in murukku was due to the larger pore volume. Water absorption in the composites was generally very low varying between 5 and $15 \%$ depending upon the wood and polymer loading. In rubber based composites, water absorption was generally lower.

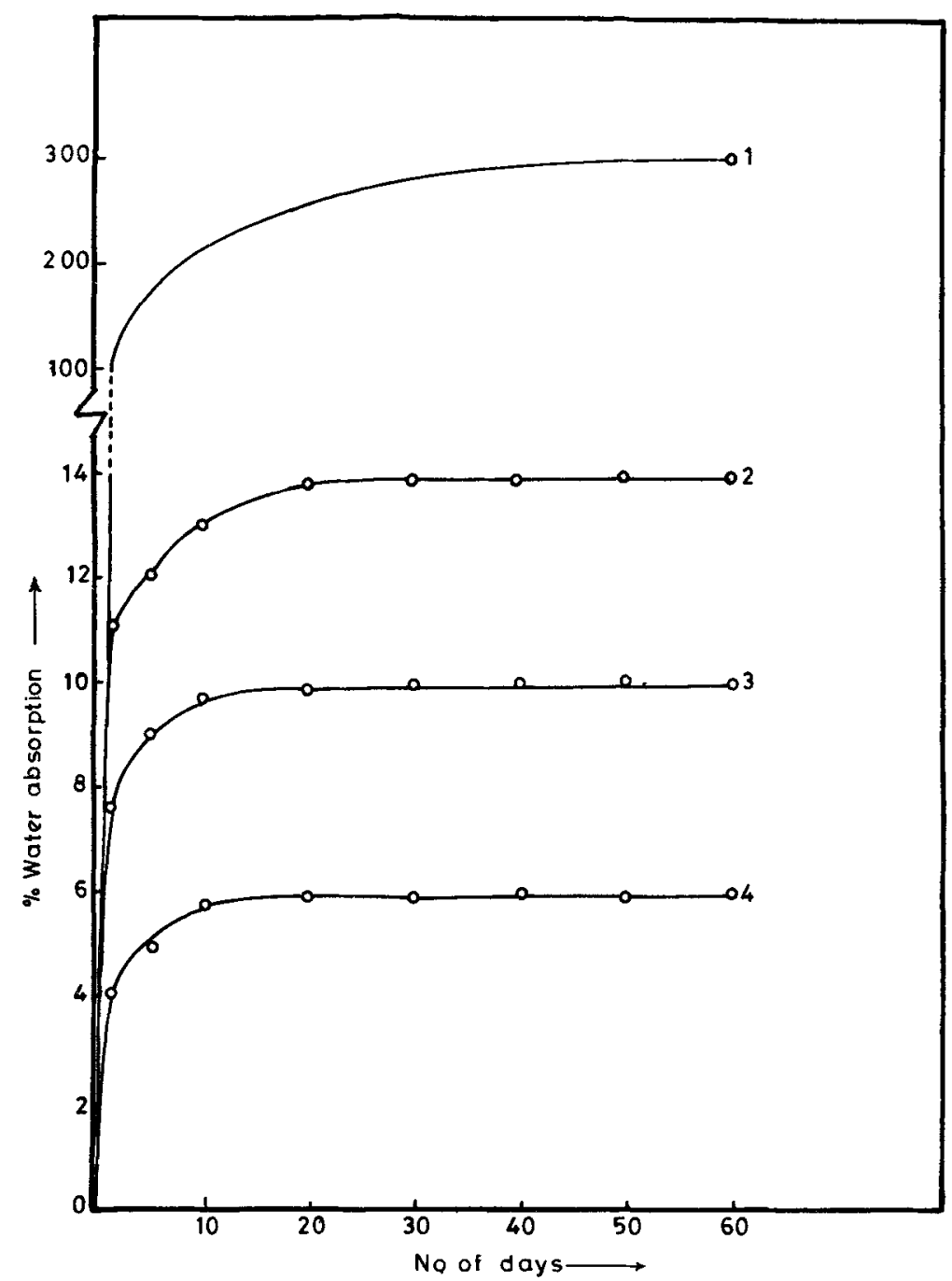

Figure 3. Water absorption in murukku based composites. 1. Control, 2. p-styrene, 3. p-MMA and 4. p-(acrylonitrile + vinyl acetate). 


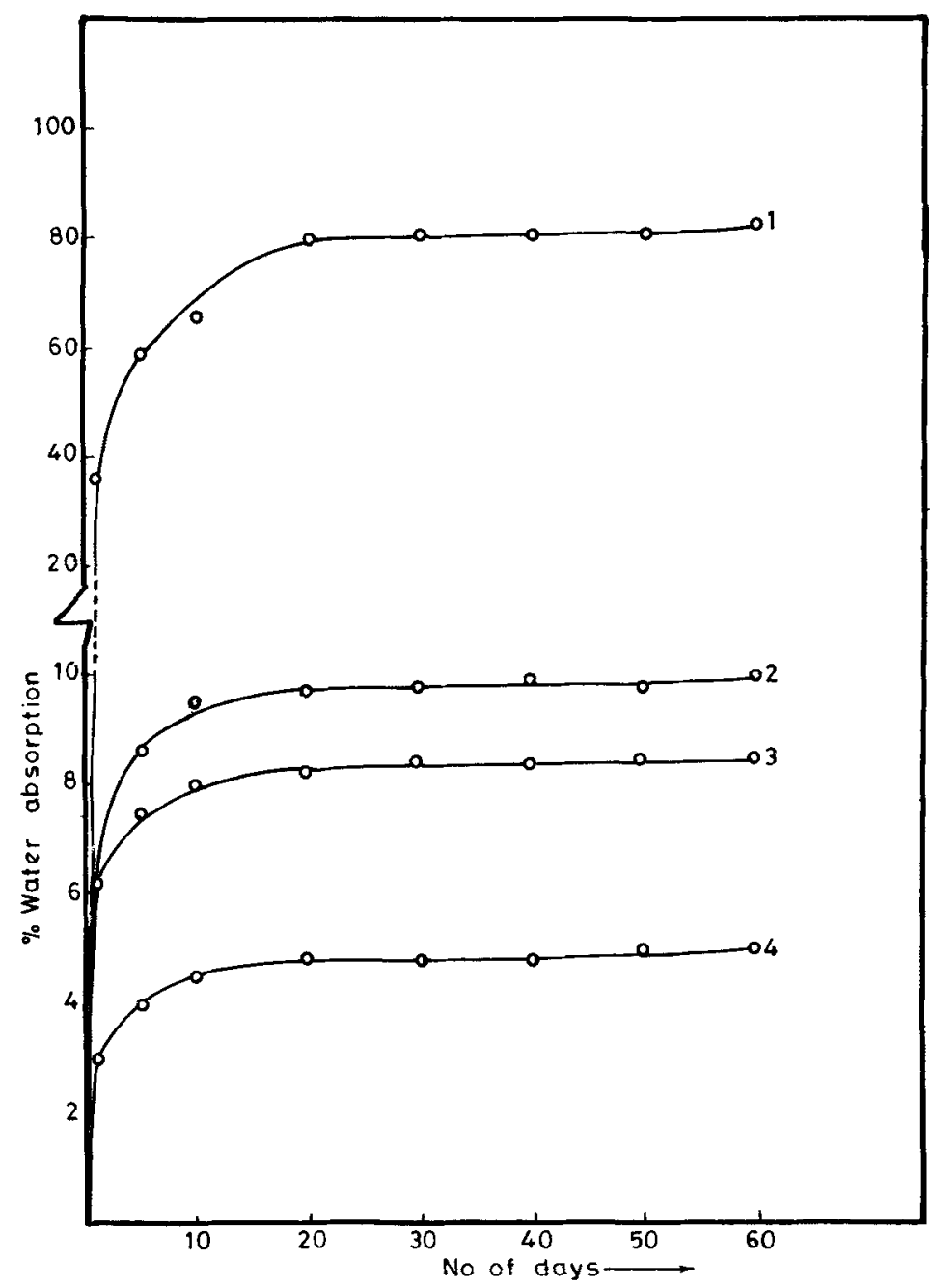

Figure 4. Water absorption in rubber based composites. 1. Control, 2. p-(acrylonitrile + vinyl acetate), 3. p-styrene and 4. p-(acrylonitrile + MMA).

\subsection{X-ray diffraction}

X-ray diffraction patterns of murukku and some of the composites based on this wood are shown in figure 5 . The diffraction patterns of untreated murukku exhibited an intense peak at $2 \theta=22^{\circ} 30^{\prime}$. This corresponded to the diffraction from the $(002)$ planes of the monoclinic unit cell of the cellulose chains. The rest of the constituents of wood gave rise to amorphous background in the X-ray pattern. These results were consistent with earlier observations (Murayama 1963).

X-ray diffraction pattern of two representative WPC samples viz. the MMAmurukku composites corresponding to low and high MCs (figure 5), clearly showed two intense peaks. One of them was identified as cellulose and the other as polymer.

It was observed that the peaks due to cellulose and polymer appeared superimposed, although a secondary peak of MMA at $22^{\circ} 30^{\prime}$ was submerged in the more intense 


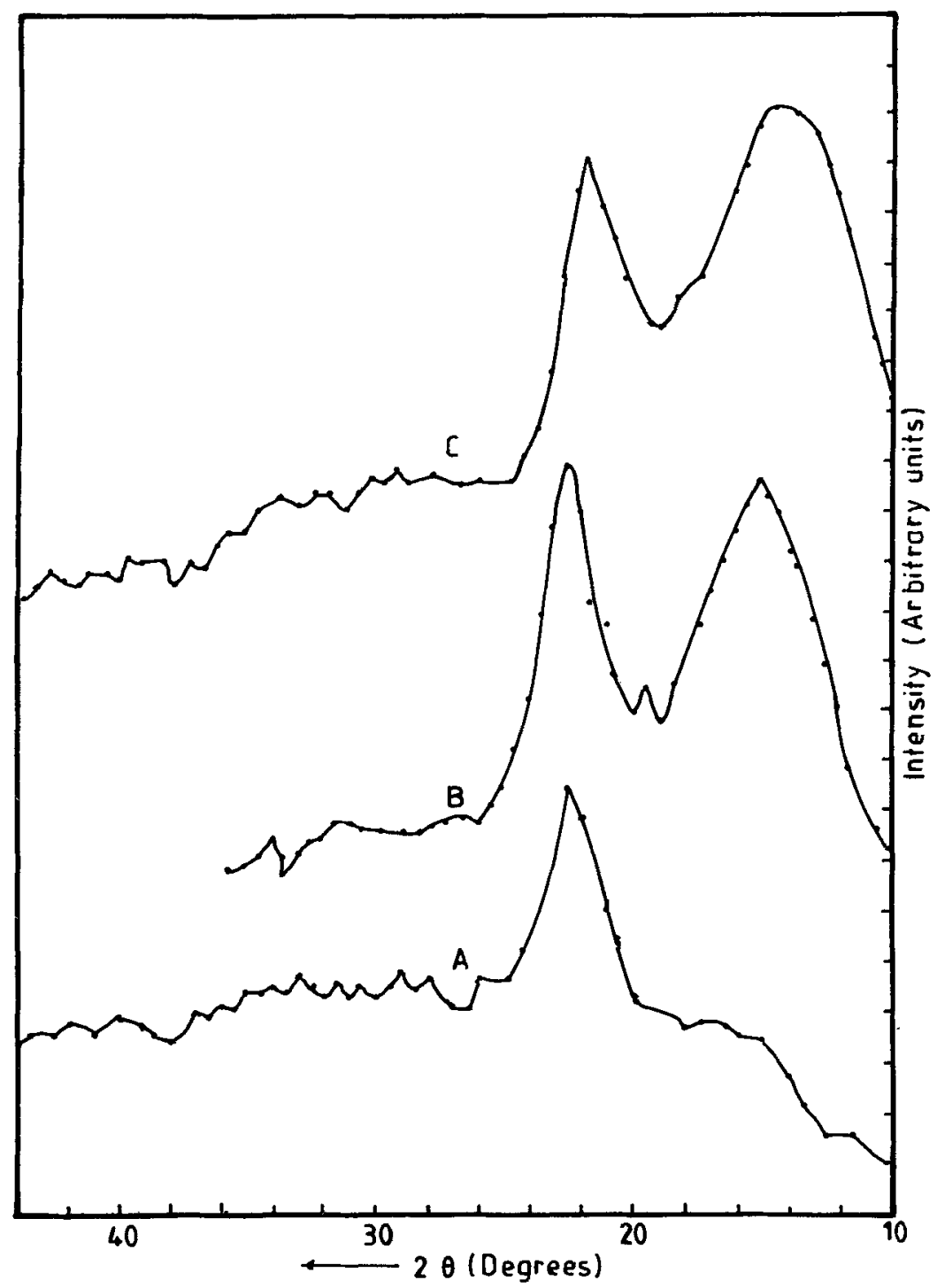

Figure 5. X-ray diffraction pattern of A. murukku wood, B. MMA-murukku composite (low $\mathrm{MC}$ ) and $\mathrm{C}$. composite (high $\mathrm{MC}$ ).

cellulose peak at the same angle. The diffraction peak due to cellulose was unaffected by the presence of the polymer which suggested that grafting of polymer onto the crystalline regions of the cellulose may not be significant irrespective of the moisture content of the starting wood sample. The polymer resided in the cell lumen and probably in the amorphous regions of the cellulose fibres. It was possible that the polymer was grafted onto the lignin as suggested by Gibson et al (1966) in which case also the crystallinity of the cellulose was unaffected. It can be concluded that moisture as a swelling agent promoting the grafting reaction may be acting in the amorphous regions of the cellulose or the lignin. The fact that radiation grafting did not affect crystallinity has been reported by Sundardi et al (1983). Diffraction scans 
of the other composites also exhibited peaks corresponding to wood and polymer being superimposed on one another.

\section{Conclusions}

WPC have been prepared from two species of softwood, viz. murukku and rubber and commercially available monomers, by vacuum impregnation and irradiation. Parameters governing the impregnation and polymerization have been investigated. Barring styrene, all other monomers polymerized in wood below the radiation dose of $2 \mathrm{Mrad}$. For styrene, a targer dose of 9 to $10 \mathrm{Mrad}$ was found necessary. The volume of pores in murukku wood was about $82 \%$ of the total volume whereas in rubber it was only $53 \%$. The impregnation efficiency was found to be lower in rubber than in murukku. There was also an overall improvement in the various mechanical properties. The use of combinations of hard and soft polymers in wood provided the desired mechanical strength to WPC. Reduction in absorption of water by WPC rendered it dimensionally more stable. X-ray analysis of the samples suggested that the degree of crystallinity of wood was unaffected by polymer incorporation. Grafting of the polymer, if any, was found to occur in the amorphous region of the cellulose fibres or in lignin.

\section{References}

Brebner K I, Schneider M H and St. Pierre L E 1985 Forest Prod. J. 3522

Czvikovazky $\mathrm{T}$ and Dobo J 1968 in Impregnated Fibrous Materials (Vienna: IAEA) p. 169

Felice A $J 1968$ in Impregnated Fibrous Materials (Vienna: IAEA) p. 71

Forest Research Institute 1961100 Years of Indian Forestry (1861-1961) II (Dehradun: Forest Research Institute)

Gibson E J, Laidlaw R A and Smith G A 1966 J. Appl. Chem. 1658

Indian Standards Institution 1966 Guide for Installation of Pressure Impregnation plants for Timber (New Delhi: Indian Standards Institution) IS: 2683-1966

Iya V K 1968 in Impregnated Fibrous Materials (Vienna: IAEA) p. 231

Mayer J A 1981 Wood Science 1449

Moore G R, Kline D E and Blankenhorn P R 1983 Wood and Fiber Sci. 15358

Murayama T 1963 Mokuzaikhogyo 1869

Rotariu G J and Mott W E 1968 in Impregnated Fibrous Materials (Vienna: IAEA) p. 190

Schaudy V R, Wendrinsky J and Proksch E 1982 Holzforschung 36197

Sundardi F, Kadariah and Marlianti 1983 J. Appl. Polymer Sci. 283123 